\title{
BMJ Open Emergency and urgent care capacity in a resource-limited setting: an assessment of health facilities in western Kenya
}

Thomas F Burke, ${ }^{1,2,3}$ Rosemary Hines, ${ }^{1}$ Roy Ahn, ${ }^{1,2,3}$ Michelle Walters, ${ }^{1}$ David Young, ${ }^{1}$ Rachel Eleanor Anderson, ${ }^{1}$ Sabrina M Tom, ${ }^{1}$ Rachel Clark, ${ }^{1}$ Walter Obita, ${ }^{3}$ Brett D Nelson ${ }^{1,2,3}$

To cite: Burke TF, Hines R, Ahn $\mathrm{R}$, et al. Emergency and urgent care capacity in a resource-limited setting: an assessment of health facilities in western Kenya. BMJ Open 2014:4:e06132.

doi:10.1136/bmjopen-2014006132

- Prepublication history for this paper is available online. To view these files please visit the journal online (http://dx.doi.org/10.1136/ bmjopen-2014-006132).

Received 16 July 2014 Revised 8 September 2014 Accepted 9 September 2014

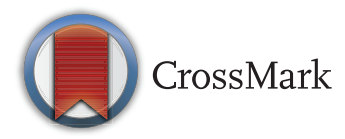

${ }^{1}$ Division of Global Health and Human Rights, Department of Emergency Medicine, Massachusetts General Hospital, Boston, Massachusetts, USA

${ }^{2}$ Harvard Medical School, Boston, Massachusetts, USA ${ }^{3}$ Sagam Community Hospital, Luanda, Kenya

Correspondence to Dr Thomas F Burke; tfburke@partners.org

\section{ABSTRACT}

Objective: Injuries, trauma and non-communicable diseases are responsible for a rising proportion of death and disability in low-income and middle-income countries. Delivering effective emergency and urgent healthcare for these and other conditions in resourcelimited settings is challenging. In this study, we sought to examine and characterise emergency and urgent care capacity in a resource-limited setting.

Methods: We conducted an assessment within all 30 primary and secondary hospitals and within a stratified random sampling of 30 dispensaries and health centres in western Kenya. The key informants were the most senior facility healthcare provider and manager available. Emergency physician researchers utilised a

semistructured assessment tool, and data were analysed using descriptive statistics and thematic coding.

Results: No lower level facilities and $30 \%$ of higher level facilities reported having a defined, organised approach to trauma. $43 \%$ of higher level facilities had access to an anaesthetist. The majority of lower level facilities had suture and wound care supplies and gloves but typically lacked other basic trauma supplies. For cardiac care, $50 \%$ of higher level facilities had morphine, but a minority had functioning ECG, sublingual nitroglycerine or a defibrillator. Only $20 \%$ of lower level facilities had glucometers, and only $33 \%$ of higher level facilities could care for diabetic

emergencies. No facilities had sepsis clinical guidelines.

Conclusions: Large gaps in essential emergency care capabilities were identified at all facility levels in western Kenya. There are great opportunities for a universally deployed basic emergency care package, an advanced emergency care package and facility designation scheme, and a reliable prehospital care transportation and communications system in resource-limited settings.

\section{INTRODUCTION}

\section{Background and importance}

Providing effective emergency and urgent care is a considerable challenge in low-income and middle-income countries. Difficulties exist

\section{Strengths and limitations of this study}

- This assessment was completed within all 30 primary and secondary hospitals and within a stratified random sampling of 30 dispensaries and health centres in two counties in western Kenya.

- Semistructured interviews were conducted among facility leadership to examine and characterise emergency and urgent care capacity in this resource-limited setting.

- Large gaps at all facility levels were identified in essential care capabilities.

- There are great opportunities for a universally deployed basic emergency care package, an advanced emergency care package and facility designation scheme, and a reliable prehospital care transportation and communications system in resource-limited settings.

- The study may not be generalisable outside of this region.

with regard to transportation, communications, equipment, facility infrastructure, medication supply lines, affordability and availability of skilled healthcare providers. Historically, infections caused by communicable diseases have been the major contributors to morbidity and mortality in resource-limited settings. However, traumatic injuries and noncommunicable diseases (NCDs), such as heart disease and cancer, are rising rapidly and have recently become recognised as significant contributors to the burden of disease in developing countries. Eighty per cent of all NCD deaths in 2008 (29 million) occurred in lowincome and middle-income countries, with cardiovascular disease, cancers and respiratory disease being the leading causes. ${ }^{1}$ Furthermore, 16000 people die globally each day from injuries alone, accounting for over $15 \%$ of the global burden of disease. Approximately $90 \%$ of these injuries occur in low-income and middle-income countries. ${ }^{2-4}$ 
Kenya is facing an epidemic of NCDs and an increasing burden of injury and trauma. Between 2003 and 2008, the proportion of deaths related to trauma in western Kenya increased from $2.5 \%$ to $5.9 \%$, with road traffic accidents (RTA) the the leading cause. ${ }^{5}$ In the past, most Kenya public health programmes focused on communicable diseases. As a consequence, Kenya has developed disease-specific clinical guidelines for HIV/AIDS, malaria, tuberculosis and other communicable diseases, but there are currently no national guidelines for emergency care. ${ }^{6} 7$ As rates of NCDs and trauma-related injuries and deaths increase, there is a growing urgency to provide adequate and organised treatment for timesensitive illnesses and injuries, such as acute myocardial infarction (AMI), stroke, trauma and sepsis.

Recent assessments performed in a select group of facilities in Nigeria, South Africa and Tanzania documented emergency and critical care services in terms of resources, routines and guidelines, while a small-scale evaluation of public emergency departments in Kenya described the most common diagnoses of presenting patients. $^{8-11}$ Other facility-level studies in Kenya have assessed inpatient care. ${ }^{12} 13$ However, no assessment of the emergency care capabilities across a region in Kenya has ever been published.
Goals of this investigation

The Division of Global Health and Human Rights in the Department of Emergency Medicine at the Massachusetts General Hospital was approached by the Kenyan Ministry of Health and asked to assess the emergency and urgent healthcare capabilities across all levels of facilities in Kisumu and Siaya counties of western Kenya. This paper reports major findings from this assessment.

\section{Healthcare provision in Kenya}

Kenya has 6626 health facilities across 47 counties, serving a population of over 43 million people. Kisumu and Siaya counties have populations of 968909 (52\% urban) and 842304 (11\% urban), respectively. ${ }^{14}$ There are a total of 150 health facilities in Kisumu (92 public, 15 non-governmental, 15 faith based and 28 private) and a total of 162 health facilities in Siaya (115 public, 7 nongovernmental, 17 faith-based and 23 private). The Kenya Essential Package for Health (KEPH) defines the levels of care in Kenya: level 1 for community-administered care and levels 2-6 for healthcare facilities (table 1) ${ }^{15}$ Levels 2, 3, 4, 5 and 6 represent dispensaries and clinics, health centres, primary hospitals, secondary hospitals and tertiary hospitals, respectively.

\begin{tabular}{|c|c|c|}
\hline Level 1 & Community & $\begin{array}{l}\text { Care outside facility in households, communities and villages } \\
\text { Maximum population served: } 5000\end{array}$ \\
\hline Level 2 & Dispensaries/clinics & $\begin{array}{l}\text { Has limited staff (nurses, public health technicians and assistants) } \\
\text { Responsible for community engagement through curative, promotive, } \\
\text { preventive and rehabilitative care at a basic level } \\
\text { Up to four beds for observation } \\
\text { Maximum population served: } 10000 \text { (rural)-15000 (urban) }\end{array}$ \\
\hline Level 3 & Health centres & $\begin{array}{l}\text { Staffed by nurses, clinical officers and occasionally doctors } \\
\text { Wider range of curative and preventive services than level } 2 \\
\text { Provide minor surgical services, like incision and drainage } \\
\text { Basic emergency preparedness } \\
\text { - } 12-49 \text { beds } \\
\text { Maximum population served: } 30000-40000\end{array}$ \\
\hline Level 4 & Primary hospitals & $\begin{array}{l}\text { Provide referral level outpatient care, curative and preventive care, surgical treatment } \\
\text { techniques and comprehensive emergency services } \\
\text { - Provide clinical services in obstetrics and gynaecology, child health, medicine, and } \\
\text { surgery and anaesthesia } \\
\text { - Inpatient care and } 24 \mathrm{~h} \text { service } \\
\text { - Minimum } 50 \text { beds } \\
\text { - Maximum population served: } 100000 \text { (rural)-200 } 000 \text { (urban) }\end{array}$ \\
\hline Level 5-6 & $\begin{array}{l}\text { Secondary/tertiary } \\
\text { hospitals }\end{array}$ & $\begin{array}{l}\text { Higher concentration of resources and personnel (medical professionals, nurses and } \\
\text { midwives) } \\
\text { Provide clinical services in medicine, general surgery and anaesthesia, paediatrics, } \\
\text { and obstetrics/gynaecology, dental, psychiatry, comprehensive accident and } \\
\text { emergency, ENT, ophthalmology, dermatology, ICU } \\
\text { Minimum } 50 \text { beds } \\
\text { - Maximum population served: } 1000000\end{array}$ \\
\hline
\end{tabular}

ENT, ear, nose, and throat; ICU, intensive care unit. 


\section{METHODS}

\section{Study design and setting}

This facility-based emergency care capabilities assessment was conducted between 1 November 2013 and 20 January 2014 in Kisumu and Siaya counties in western Kenya. All 30 level 4 and level 5 facilities in the two counties (there are no level 6 facilities in these counties) were selected for assessment. Selection of 30 additional facilities occurred via randomised stratified sampling of each additional type of facility-dispensary, health centre and health clinic. The criterion for inclusion was an open healthcare facility currently providing health services; there were no restrictions based on geography or accessibility.

\section{Methods and measurements}

This facility-based emergency care capabilities assessment utilised semistructured, key-informant interviews using a data collection instrument designed by the study authors. The key informants were the most senior institution staff members identified during the day of the assessment-typically the chief medical officer and/or senior administrator. The assessment tool drew from existing models of facility assessment in South Africa, Pakistan and Tanzania, as well as from the WHO Guidelines for Essential Trauma Care..$^{9} 10 \quad 16 \quad 17$ The assessment tool was refined by expert consultation with the team's emergency physicians and public health epidemiologists, and covered eight domains: facility demographics, referral services, personnel, economics, supplies and laboratory, trauma, critical care and anaesthesia. The interviews consisted of open-response questions related to healthcare services, most common conditions of patients presenting for care, provider capabilities, equipment, supplies and medications. Qualitative questions pertained to attitudes and perceptions related to provider morale, co-operation and communication between referring and receiving health facilities, and recommendations for continuing education and referral services.

The key-informant interviews were conducted by our field research team-consisting at all times of at least one emergency physician and one research assistant. Three different emergency physicians were involved throughout the data collection process. The delivery of questions and interview structure were discussed a priori by all three physician interviewers in order to standardise the interview process. Participants were provided an overview of the project, and the voluntary and confidential nature of the assessment was described. All participants gave verbal consent prior to participation.

\section{Analysis}

Data were analysed using standard descriptive and frequency analyses, utilising Microsoft Excel 2007 (Seattle, Washington, USA). Qualitative research methods involved thematic analysis of interviews in order to best understand emergent findings.

\section{RESULTS}

A key informant at each of the 60 facilities was surveyed between 1 November 2013 and 20 January 2014. The facility sites were a mix of dispensaries/health clinics, health centres, primary hospitals and secondary hospitals, as shown in table 2. (There are no tertiary hospitals in Kisumu or Siaya counties). The 60 key informants comprised 10 chief medical officers (all at the hospital level), 39 nurse managers (facility matron) and 11 lead clinical officers.

\section{Level 2 and 3 facilities}

\section{Common conditions}

Key informants were asked by open response to list the 10 most common emergent and urgent conditions presenting to their health facility. The most frequently reported conditions at level 2 and 3 facilities were (in order of reporting frequency) malaria (30 of 30 facilities, $100 \%)$, diarrhoea $(26 / 30,87 \%)$, upper respiratory infections $(24 / 30,80 \%)$, skin infections $(18 / 30,60 \%)$, sexually transmitted infections $(15 / 30,50 \%)$, pneumonia $(14 / 30,47 \%)$ and RTAs/trauma $(9 / 30,30 \%)$.

\section{Trauma and injury}

When asked if their level 2 and 3 facilities have a specific approach to a trauma patient that differs from how they approach a medical patient, $0 \%$ of key informants answered in the affirmative. In response to how well respondents felt their facility can handle major trauma, all 30 said they refer. Twenty-six $(87 \%)$ of the 30 said they refer immediately, and $4(13 \%)$ said they try to provide first aid and then refer. The majority of providers $(21 / 30,70 \%)$ said their facility is poorly equipped to handle broken bones.

The majority of level 2 and 3 facilities had suture and wound care supplies $(26 / 30,87 \%)$ and gloves $(27 / 60$, $90 \%$; table 3$)$. Few of these facilities had oxygen $(7 / 30$, $23 \%)$ and splinting/casting supplies $(3 / 30,10 \%)$, and none had blood for transfusion $(0 / 30,0 \%)$.

\section{Critical care}

When asked about the standard procedure for treating someone with a possible heart attack, all 30 providers at level 2 and 3 facilities reported that their facility refers. Eighteen $(60 \%)$ of the 30 reported referring patients immediately, $8(27 \%)$ said they treat symptoms (eg, painkillers, oxygen) and then refer, and $4(13 \%)$ said they

Table 2 Health facilities studied in Kisumu and Siaya counties in Kenya; November 2013-January 2014

\begin{tabular}{lccr}
\hline Type of health facility & Kisumu & Siaya & Total \\
\hline Dispensary/health clinic (level 2) & 9 & 12 & $\mathbf{2 1}$ \\
Health centre (level 3) & 6 & 3 & $\mathbf{9}$ \\
Primary hospitals (level 4) & 18 & 6 & $\mathbf{2 5}$ \\
Secondary hospitals (level 5) & 4 & 1 & $\mathbf{5}$ \\
Total & $\mathbf{3 8}$ & $\mathbf{2 2}$ & $\mathbf{6 0}$ \\
\hline
\end{tabular}


Table 3 Functioning supplies and equipment at health facilities in Kisumu and Siaya, Kenya (number of facilities)

\begin{tabular}{|c|c|c|c|c|c|}
\hline & $\begin{array}{l}\text { Level } 2 \\
\mathrm{n}=21(\%)\end{array}$ & $\begin{array}{l}\text { Level } 3 \\
n=9(\%)\end{array}$ & $\begin{array}{l}\text { Level } 4 \\
\mathrm{n}=25(\%)\end{array}$ & $\begin{array}{l}\text { Level } 5 \\
n=5(\%)\end{array}$ & $\begin{array}{l}\text { Total } \\
n=60(\%)\end{array}$ \\
\hline \multicolumn{6}{|l|}{ General } \\
\hline Gloves & $20(95)$ & $7(78)$ & $24(96)$ & $5(100)$ & $56(93)$ \\
\hline Face masks & $10(48)$ & $4(44)$ & $21(84)$ & $5(100)$ & $40(67)$ \\
\hline Gowns & $3(14)$ & $4(44)$ & $17(68)$ & $5(100)$ & $29(48)$ \\
\hline Monitored beds & NA & $\mathrm{NA}$ & $1(4)$ & $4(80)$ & $6(10)$ \\
\hline Central line kits & NA & NA & $1(4)$ & $4(80)$ & $5(8)$ \\
\hline Suction & $5(24)$ & $4(44)$ & $19(76)$ & $4(80)$ & $32(53)$ \\
\hline Blood pressure cuffs & $18(86)$ & $6(67)$ & $23(92)$ & $5(100)$ & $52(87)$ \\
\hline Splint/cast supplies & $2(10)$ & $1(11)$ & $14(56)$ & $4(80)$ & $21(35)$ \\
\hline Suture and wound care supplies & $18(86)$ & $8(89)$ & $23(92)$ & $5(100)$ & $54(90)$ \\
\hline Defibrillator & $1(5)$ & $0(0)$ & $1(4)$ & $3(60)$ & $5(8)$ \\
\hline Back-up power & $1(5)$ & $2(22)$ & $14(56)$ & $5(100)$ & $22(42)$ \\
\hline Chest tube trays & $1(5)$ & $1(11)$ & 3 (12) & $5(100)$ & $10(17)$ \\
\hline \multicolumn{6}{|l|}{ Laboratory/diagnostics } \\
\hline Ultrasound & $1(5)$ & $0(0)$ & $9(36)$ & $5(100)$ & $15(25)$ \\
\hline ECG & $0(0)$ & $1(11)$ & 3 (12) & $3(60)$ & 8 (13) \\
\hline X-ray & $1(5)$ & $0(0)$ & $12(48)$ & $5(100)$ & $18(30)$ \\
\hline Otoscope & $5(24)$ & $4(44)$ & $14(56)$ & $5(100)$ & $28(47)$ \\
\hline Ophthalmoscope & $4(19)$ & $4(44)$ & $13(52)$ & $5(100)$ & $26(43)$ \\
\hline Glucometer & $3(14)$ & $3(33)$ & $23(92)$ & $5(100)$ & $34(57)$ \\
\hline \multicolumn{6}{|l|}{ Medications } \\
\hline Nitroglycerine & $0(0)$ & $1(11)$ & $4(16)$ & $2(40)$ & 7 (12) \\
\hline Antibiotics & $16(76)$ & $8(89)$ & $22(88)$ & $5(100)$ & $51(85)$ \\
\hline Opiates & $0(0)$ & $0(0)$ & $10(40)$ & $5(100)$ & $15(25)$ \\
\hline Insulin & 4 (19) & $1(11)$ & $19(76)$ & $5(100)$ & $29(48)$ \\
\hline Pressors & NA & NA & $23(92)$ & $5(100)$ & $48(80)$ \\
\hline General and regional anaesthesia & NA & NA & $8(32)$ & $5(100)$ & $13(22)$ \\
\hline \multicolumn{6}{|l|}{ Airway/breathing } \\
\hline Oxygen & $5(24)$ & $2(22)$ & $20(80)$ & $5(100)$ & $32(53)$ \\
\hline CPAP/BPAP machine & NA & $\mathrm{NA}$ & $0(0)$ & $1(20)$ & $1(2)$ \\
\hline Ambubag & $8(38)$ & $1(11)$ & $20(80)$ & $5(100)$ & $34(57)$ \\
\hline Intubation supplies & $2(10)$ & $4(44)$ & $12(48)$ & $5(100)$ & $23(38)$ \\
\hline
\end{tabular}

check vitals and then refer. Of the 30 level 2 and 3 facilities, one had sublingual nitroglycerine.

The majority of providers $(29 / 30,93 \%)$ at the lower level facilities said that their facility is ill prepared to handle possible diabetic ketoacidosis (DKA) and must refer all cases. Overall, six (20\%) Level 2 and 3 facilities had a glucometer and 5 (17\%) had insulin.

In regard to a standard procedure for cases of possible sepsis, $15(50 \%)$ of the 30 providers at Level 2 and 3 facilities said they refer, $11(37 \%)$ reported providing treatment without referral (eg, antibiotics, intravenous fluids), and $4(13 \%)$ said that they did not know how to approach sepsis. A majority of the level 2 and 3 facilities $(24 / 30,80 \%)$ had antibiotics.

\section{Facility levels 4 and 5}

\section{Common conditions}

The most frequently reported presenting emergent and urgent conditions at level 4 and 5 facilities were similar to those at level 2 and 3 facilities. They are (in order of reporting frequency) malaria $(30 / 30,100 \%)$, diarrhoea $(22 / 30,73 \%)$, sexually transmitted infections $(21 / 30$,
$70 \%)$, pneumonia $(21 / 30,70 \%)$, RTAs/trauma $(18 / 30$, $60 \%)$ and upper respiratory infections $(16 / 30,53 \%)$.

Trauma and injury

Nine $(30 \%)$ providers at level 4 and 5 facilities reported that their facility has an organised approach to trauma (eg, emergency team with assembly point). When asked if they are notified in advance of patients arriving at the hospital, $4(13 \%)$ answered in the affirmative.

In a review of basic trauma supplies in level 4 and 5 facilities, 97\% had gloves, 93\% had suture and wound care materials, and $83 \%$ had oxygen. All five of the level 5 facilities had chest tubes and X-ray capability, and four of the five had splinting and casting supplies. Three (12\%) of the 25 level 4 facilities had chest tubes and 12 $(48 \%)$ had X-ray capability. Sixteen $(64 \%)$ of the 25 level 4 facilities, and all five of the level 5 facilities had blood available for transfusion. Seventeen (57\%) providers at level 4 and 5 facilities reported that their facility did not have access to a trained provider who can administer general or regional anaesthesia. 


\section{Critical care}

When asked about the diagnosis and treatment of someone presenting with a possible AMI, 20 (80\%) of 25 providers at level 4 hospitals reported that their facility refers, $11(44 \%)$ reported that their facility stabilises (eg, oxygen or first aid) and then refers, and $9(30 \%)$ reported that their facility refers immediately. Five (20\%) providers at level 4 facilities reported that their facility provides diagnostic and treatment services without referral (eg, ACE inhibitors, $\beta$ blockers or aspirin). All 5 level 5 facilities reported giving oxygen to patients with suspected AMI, while three reported providing aspirin, two reported providing morphine and one reported providing epinephrine. Several of the level 4 and 5 facilities were lacking in supplies and equipment to manage cardiac emergencies. Fifteen (50\%) facilities had morphine, 6 (20\%) had a functioning ECG machine, $6(20 \%)$ had nitroglycerine, and $4(13 \%)$ had a defibrillator.

Ten $(33 \%)$ of 30 providers at level 4 and 5 facilities reported that their facility is well prepared to manage DKA. A majority of level 4 and 5 facilities had a glucometer $(28 / 30,93 \%)$ and insulin (24/30, 80\%).

When asked about a standard procedure for cases of sepsis, the vast majority $(29 / 30,97 \%)$ of level 4 and 5 facilities reported providing some treatment for sepsis (eg, antibiotics, intravenous fluids), but none had standardised clinical care guidelines. Twenty-three (92\%) of the 25 level 4 facilities and all five of the level 5 facilities had vasopressor agents. Twenty-two $(88 \%)$ of the 25 level 4 facilities and all five of the level 5 facilities had antibiotics.

\section{DISCUSSION}

With an increasing number of NCDs, RTAs and other time-sensitive illnesses and injuries, the provision of emergency care in low-middle and middle-income countries is taking on increasing importance. Our study illustrates that essential emergency and urgent care is severely lacking in western Kenya. Limited communication, infrastructure, supplies and properly trained human resources all negatively impact the ability to deliver quality emergency and urgent healthcare.

Although by definition level 2 and 3 facilities in Kenya are not designed nor expected to provide comprehensive care for acutely ill patients, we elected to study their capabilities around emergency care since community members often present to them with acute lifethreatening illnesses and injuries. We discovered that virtually all of the 30 level 2 and 3 facilities we studied were unable to respond to the essential needs of patients presenting with acute trauma, a possible heart attack, diabetic emergencies or sepsis. Most facilities reported transferring patients without even basic assessments or interventions. Few facilities had any organised approach in transferring a patient or notifying the receiving facility.

The authors view the level 2 and 3 facility findings as a compelling call to action for the development of a contextually appropriate, standardised basic level training and materials package for emergency care. For example, a training programme in the essentials of emergency care for level 2 and 3 facilities should include the development of a standard approach to all acute care patients: basic assessment and intervention of airway, breathing and circulation; taking and interpreting vital signs; methodical total body assessment; haemorrhage control; immobilisation and splinting of potential injuries; capabilities of providing basic high-impact diagnostics and interventions (eg, point-of-care glucose, ECG, aspirin, antibiotics, splints); and a pre-established reliable and rapid referral and notification plan.

While emergent and urgent conditions present frequently to level 4 and 5 facilities, we discovered that the hospitals' capabilities varied considerably. While all of the 30 facilities had gaps across each of the domains we studied, many of the gaps at the level 4 facilities were quite profound. Overall, some of the more salient findings in the level 4 and 5 facility assessments were as follows: $70 \%$ do not have a standardised approach to trauma, few have the basic materials necessary to manage trauma (eg, chest tube, blood), less than half have a functioning X-ray machine, less than half $(43 \%)$ of the operating theatres have access to an anaesthetist, only 6 of 30 have EKG machines or nitroglycerine, most do not give aspirin for heart attacks, few are able to provide care for DKA, and no facility had a standardised approach to sepsis.

The findings from our level 4 and level 5 facility assessment demonstrate an urgent need for a system-wide intervention, targeting the unmet higher level facility needs of the acutely ill and injured. Many of the level 4 and 5 facilities did not meet the most basic standard for the essentials of emergency care delivery that we believe can-and should-be universally implemented at all lower level facilities. We propose that in addition to every facility being brought up to the basic level, a second package in essentials of advanced emergency care should be developed and deployed to select level 4 and 5 facilities. These selected facilities, once meeting standards for training, materials and infrastructure, should then be designated and widely recognised and supported as centres of excellence for advanced emergency care, and thereby capable of providing quality assessment and initial stabilisation of all emergent and urgent conditions.

Access to quality prehospital care services was universally poor in our study sample and can be seen as an opportunity for organisation and improvement. A basic prehospital system should be created by establishing a mechanism to access reliable transportation staffed with personnel who have basic life-support skills. Elsewhere, it has been shown that training lay people in the community, such as community health workers or public transportation drivers to function as prehospital care providers, can greatly improve the quality of emergency care. $^{18}$ Additionally, a standardised communication 
method ought to be instituted. For example, in Sierra Leone, it has been shown that equipping remote health facilities and traditional birth attendants with radio receivers linked to referral hospitals can shorten response times and reduce maternal deaths. ${ }^{19}$

Although not addressed in this study, it is most likely that these findings would be similar elsewhere across sub-Saharan Africa. If this assessment is indeed generalisable, the authors believe that the development of a set of standardised packages for basic and advanced essentials of emergency care in low-resource settings, as well as designating centres of excellence for advanced emergency care, should be a priority for the WHO and other stakeholders. The African Federation for Emergency Medicine has been developing consensus recommendations for emergency care packages for various facility levels. $^{20}$

Our study had several limitations. Although we believe the lessons learnt are representative of counties in Kenya and other low-resource settings globally, our findings are not definitively generalisable beyond the two counties surveyed. Furthermore, we recognise that elements of our survey may have been limited by social desirability bias. Although we tried to mitigate this with the confidential and voluntary nature of our survey and by explaining the purpose of our study, participants may not have felt comfortable reporting problems or inadequacies in their facilities. While our research staff included a local Kenyan who was present at all site visits and functioned as a language and cultural ambassador, language and cultural differences may have contributed to confounding variables. Furthermore, while informants were selected based on their senior leadership roles and expertise with the operations of their facility, their responses might not have always accurately reflected opinions of the majority of providers at the facility.

In conclusion, with an increasing epidemic of NCDs and an increasing burden of injury and trauma in lowresource areas, access to quality essential emergency and urgent care services is critical for the health of surrounding communities. Our 60-facility assessment in western Kenya identified significant widespread gaps in current emergency care capabilities, particularly in identifying and appropriately caring for victims of trauma, AMI, diabetic emergencies and sepsis. There are great opportunities for development of a universally deployed basic package in the essentials of emergency care, a selectively implemented package in the essentials of advanced emergency care, a centre of excellence for emergency care facility designation scheme, and a reliable prehospital care transportation and communications system. Additionally, the profound gap in readily available trained anaesthetists requires immediate attention.

Contributors TFB was involved in the study design, implementation, analysis and writing of the manuscript. RA was involved in the study analysis and writing of the manuscript. RA was involved in the study design, implementation, analysis and writing of the manuscript. MW, DY, REA, ST, RC and WO were involved in study design and data collection. BDN was involved in the study design, implementation, analysis and writing of the manuscript. All authors have reviewed, edited and approved the final submission. TFB takes responsibility for the paper as a whole.

Funding This study was funded internally and by in-kind donation by the authors' Division of Global Health and Human Rights at Massachusetts General Hospital.

\section{Competing interests None.}

Ethics approval This study was reviewed and approved by the Institutional Review Board of Partners Healthcare (Boston, Massachusetts, USA) and the Ministry of Health of Kenya.

Provenance and peer review Not commissioned; externally peer reviewed.

Data sharing statement Additional data are available by emailing tfburke@partners.org

Open Access This is an Open Access article distributed in accordance with the Creative Commons Attribution Non Commercial (CC BY-NC 4.0) license, which permits others to distribute, remix, adapt, build upon this work noncommercially, and license their derivative works on different terms, provided the original work is properly cited and the use is non-commercial. See: http:// creativecommons.org/licenses/by-nc/4.0/

\section{REFERENCES}

1. World Health Organization. Global status report on noncommunicable diseases 2010. Geneva: World Health Organization, 2010.

2. Peden M, McGee K, Sharma G. The injury chartbook: a graphical overview of the global burden of injuries. Geneva: World Health Organization, 2002.

3. Gosselin R, Spiegel D, Coughlin R, et al. Injuries: the neglected burden in developing countries. Bull World Health Organ 2009;87:246.

4. Mock C, Lormand JD, Goosen J, et al. Guidelines for essential trauma care. Geneva: World Health Organization, 2004.

5. Odhiambo FO, Beynon CM, Ogwang S, et al. Trauma-related mortality among adults in rural western Kenya: characterising deaths using data from a health and demographic surveillance system. PLOS ONE 2013;8:e79840.

6. Ministry of Health, Government of Kenya. Guidelines for antiretroviral drug therapy in Kenya. 2011. http://www.who.int/hiv/pub/guidelines/ kenya_art.pdf (accessed 7 May 2014).

7. Ministry of Public Health and Sanitation. Guidelines on management of leprosy and tuberculosis. 2009. http://www.who.int/hiv/pub/ guidelines/kenya_tb.pdf (accessed 7 May 2014).

8. Baker T, Lugazia E, Eriksen J, et al. Emergency and critical care services in Tanzania: a survey of ten hospitals. Bull World Health Organ 2013;13:140.

9. Wallis LA, Garach SR, Kropman A. State of emergency medicine in South Africa. Int J Emerg Med 2008;1:69-71.

10. Wen LS, Oshiomogho JI, Eluwa Gl, et al. Characteristics and capabilities of emergency departments in Abuja, Nigeria. Emerg Med J 2012;29:798-801.

11. Wachira BW, Wallis LA, Geduld H. An analysis of the clinical practice of emergency medicine in public emergency departments in Kenya. Emerg Med J 2012;29:473-6.

12. Mwaniki P, Ayieko P, Todd J, et al. Assessment of paediatric inpatient care during a multifaceted quality improvement intervention in Kenyan district hospitals: Use of prospectively collected case record data. BMC Health Serv Res 2014;14:312.

13. Irimu GW, Gathara D, Zurovac D, et al. Performance of health workers in the management of seriously sick children at a Kenyan tertiary hospital: Before and after a training intervention. PLOS ONE 2012;7:e39964.

14. Commission on Revenue Allocation (2011) Kenya County Fact Sheets. http://siteresources.worldbank.org/INTAFRICA/Resources/ 257994-1335471959878/Kenya_County_Fact_Sheets_Dec2011.pdf (accessed 7 May 2014).

15. Luoma M, Doherty J, Muchiri S, et al. Kenya Health System Assessment 2010. Bethesda, MD: Health Systems 20/20 project Abt Associates Inc., 2010.

16. World Health Organization. Guidelines for essential trauma care. Geneva: World Health Organization, 2004. 
17. Razzak JA, Hyder AA, Akhtar T, et al. Assessing emergency medical care in low-income countries: a pilot study from Pakistan. BMC Emerg Med 2008;8:8.

18. Mock CN, Tiska M, Adu-Ampofo M, et al. Improvements in prehospital trauma care in an African country with no formal emergency medical services. J Trauma 2002;53:90-7.
19. Samai O, Senegeh P. Facilitating emergency obstetrical care through transportation and communication, Bo, Sierra Leone. Int J Gynaecol Obstet 1997;59(Suppl 2):S157-64.

20. Calvello E, Reynolds T, Hirshon JM, et al. Emergency care in sub-Saharan Africa: results of a consensus conference. Afr J Emerg Med 2013;3:42-8. 